\title{
Behavioral and Neurobiological Assessments of Predator-Based Fear Conditioning and Extinction
}

\author{
Joshua D. Halonen 1,2, Phillip R. Zoladz ${ }^{3}$, Collin R. Park ${ }^{2,5}$, David M. Diamond ${ }^{2,4,5 *}$ \\ ${ }^{1}$ Department of Psychology, University of Tampa, Tampa, Florida, USA \\ ${ }^{2}$ Department of Psychology, University of South Florida, Tampa, Florida, USA \\ ${ }^{3}$ Department of Psychology, Sociology \& Criminal Justice, Ohio Northern University, Ada, Ohio, USA \\ ${ }^{4}$ Department of Molecular Pharmacology \& Physiology, University of South Florida, Tampa, Florida, USA \\ ${ }^{5}$ Center for Preclinical \& Clinical Research on PTSD, University of South Florida, Tampa, Florida, USA \\ Email: *ddiamond@mail.usf.edu
}

Received 24 May 2016; accepted 19 July 2016; published 22 July 2016

Copyright (C) 2016 by authors and Scientific Research Publishing Inc.

This work is licensed under the Creative Commons Attribution International License (CC BY).

http://creativecommons.org/licenses/by/4.0/

(c) () Open Access

\begin{abstract}
Shock, immobilization, and exposure to predator-related stimuli have all been used to study fear conditioning in rodents, but they have never been used in conjunction in a single study. Experiment 1 compared the effects of these three reinforcers, alone and in various combinations, on the expression of long-term conditioned fear memory and extinction in adult male rats. Whereas foot shock conditioning, alone, was rapidly extinguished; the combination of immobilization and cat exposure, or all 3 stimuli together, produced a significant increase in the magnitude of fear conditioning and greater resistance to extinction, which persisted for at least 5 weeks post-training $(p<$ 0.05). Experiment 2 assessed the role of the hippocampus in predator-based context and cued fear conditioning. Pharmacological suppression of hippocampal activity during fear conditioning produced a selective impairment of contextual, but not cued, fear memory. Experiment 3 investigated the effects of sleep deprivation prior to fear conditioning on the expression of fear memory. This experiment demonstrated that pre-training sleep deprivation blocked the expression of contextual (hippocampal-dependent), but not cued (hippocampal-independent), fear memory. Overall, this series of experiments has extended the use of predator exposure in conjunction with conventional reinforcers, such as foot shock and immobilization, to advance our understanding of the neurobiology of traumatic memory.
\end{abstract}

\section{Keywords}

Fear Conditioning, Predator Exposure, Hippocampus, Sleep Deprivation

\footnotetext{
"Corresponding author.
}

How to cite this paper: Halonen, J.D., Zoladz, P.R., Park, C.R. and Diamond, D.M. (2016) Behavioral and Neurobiological Assessments of Predator-Based Fear Conditioning and Extinction. Journal of Behavioral and Brain Science, 6, 337-356. 


\section{Introduction}

Fear associations to environmental stimuli are part of an evolutionary defensive behavior system that protects individuals from danger [1]-[4]. Fear conditioning paradigms in a broad range of species [5]-[7] have investigated how environmental stimuli become associated with aversive events [8] [9], and the neural mechanisms underlying associative learning have been studied [10] [11]. Moreover, understanding the neurobiological basis of fear conditioning should enhance our understanding of how traumatic experiences produce pathologically intense and intrusive memories which underlie psychiatric disorders, such as post-traumatic stress disorder (PTSD).

A vast literature has demonstrated that the amygdala is necessary for fear-based memory associations to be made [12]-[16]. Lesions of the amygdala block Pavlovian fear conditioning [17] and prevent freezing expressed to contexts and cues associated with foot shock [18]-[23]. Lesions of the amygdala made one week before or up to one month after training can block memory-related (freezing) behavior [19]. More recent work targeting the molecular biology of amygdala neurons has confirmed the crucial role of the lateral and basolateral subdivisions of the amygdala in the formation and expression of fear memories [24]-[27].

Whereas the amygdala is necessary for fear conditioning to occur, the hippocampus is involved in the processing of the representation of the components of the environment (context) in which the fear experience occurred [13] [23] [28] [29]. Investigations of the role the hippocampus plays in Pavlovian contextual fear conditioning have shown that lesions of the dorsal hippocampus made prior to [23] [30]-[33] or soon after [34] conditioning block freezing upon re-exposure of the subject to the conditioning context. In hippocampus-lesioned animals, associations formed to discrete cues presented in conjunction with the aversive stimulus remain intact, as indicated by freezing to discrete stimuli, such as auditory cues. Parsons \& Otto [35] used the GABA receptor agonist muscimol to demonstrate that temporary inactivation of the dorsal hippocampus produced contextspecific fear memory deficits. In the past decade novel approaches employing optogenetic manipulation of cell activity have confirmed and extended our understanding of the necessary involvement of the hippocampus in the formation and consolidation of the contextual features of fear conditioned memory [24] [25] [36]-[38].

In an ethologically relevant approach to the study of the neurobiology of fear, numerous laboratories have assessed the effects of predator exposure, or predator-based cues, on rodent brain, behavior and memory [39]-[53]. One group, in particular, has conducted an extensive behavioral and anatomical assessment of predator-based fear conditioning. Canteras and co-workers have identified predator-specific fear circuitry in the brain [54] [55], with evidence that sub-nuclei in the amygdala, thalamus, periaqueductal grey and hypothalamus are responsive to sensory and memory-specific processing of predator cues [22] [53] [56]-[58].

Our group has also examined the influence of predator exposure on the brain and behavior, with an emphasis on memory-related functions of the amygdala and hippocampus. We have shown that cat exposure impairs rat hippocampus-dependent memory [59]-[61] and blocks hippocampal synaptic plasticity [62]. It is noteworthy that we have shown that the same stressor that blocks hippocampalsynaptic plasticity (cat exposure) enhances synaptic plasticity in the amygdala [63]. In speculative reviews we have discussed how the formation of new fear memories with cat exposure can impair spatial (hippocampal) memory, and simultaneously produce strong hippocampal and amygdala-based memories of the traumatic experience [64]-[66].

In addition to our studies on acute predator exposure, synaptic plasticity and memory, we have developed a predator-based animal model of PTSD. We reported that rats exposed to a cat on two occasions, occurring within a 31-day period of chronic social instability, exhibited numerous behavioral and physiological outcomes which resemble the clinical symptoms of PTSD (for reviews see [67] \& [68]). The most relevant observation from this work with regard to the current study is our finding that rats exhibit a long-term fear conditioned memory of the context and cue associated with the cat exposure component of chronic psychosocial stress [69][71] which persisted for at least 4 months [72].

The current series of experiments is an extension of the fear conditioning component of our PTSD model, with an emphasis on exploring factors that influence the magnitude and durability of the predator-based fear memory. Specifically, in the three experiments described here we have examined: 1) the magnitude of contextual and cued fear memory when the reinforcement was predator exposure, shock or immobilization, individually and when multiple reinforcers were presented together; 2) the rate of fear memory extinction when the conditioning stimuli were delivered over the course of 3 weeks of extinction training; 3) the influence of pharmacological inactivation of the dorsal hippocampus on contextual and cued predator-based fear conditioning; and 4) 
the influence of sleep deprivation on the expression of contextual and cued predator-based fear conditioning.

\section{Experiment 1}

In Experiment 1, we assessed the effects of different aversive stimuli on context and cued fear conditioning and extinction. This experiment addressed the hypothesis that shock, immobilization, and predator exposure, alone or in combination, would result in a synergistic amplification of the magnitude, duration and resistance to extinction of the fear conditioned memory. Standard foot shock conditioning was used as an unconditioned stimulus (US) to compare its effects, as an established conditioning stimulus, with immobilization and cat exposure. Immobilization was utilized because restraint stress enhances fear conditioning and resistance to extinction [73]-[75]. Immobilization also produces alterations in neurotrophic factors, such as glutathione [76], brain-derived neurotrophic factor [77] [78] and the immediate early gene c-fos [79]. Furthermore, immobilization influences the hypothalamic pituitary adrenal (HPA) axis and adrenergic systems modulated by glucocorticoid receptors in the brainstem, hypothalamus, and locus coeruleus [80]. Therefore, immobilization, alone, was assessed as a US. Predator exposure was also used as a US, alone and in conjunction with foot shock and immobilization. Overall, Experiment 1 was designed to assess the potential combined effects of the delivery of combinations of immobilization, predator exposure and shock on the persistence and magnitude of fear conditioning memory, as well as its resistance to extinction.

\subsection{Method}

Animals. A total of 48 male Sprague-Dawley rats (Charles River Laboratories) approximately 8 weeks old and weighing 225 - $250 \mathrm{~g}$ upon arrival were used in this experiment. All rats were acclimated to the vivarium and cage cleanings for at least 7 days before any experimental manipulations were performed. Rats were housed 2 per cage in standard Plexiglas cages $(46 \times 25 \times 21 \mathrm{~cm})$ with tap water and rat chow available ad libitum. The animal housing room was maintained at $20^{\circ} \mathrm{C} \pm 1{ }^{\circ} \mathrm{C}$ with a humidity range of $60 \% \pm 3 \%$ and a 12-hr light cycle (lights on at 700). All procedures were approved by the Institutional Animal Care and Use Committee at the University of South Florida.

Conditioning Apparatus and General Procedure. All animals received the same general treatment outlined as follows. Rats were transported in their home cage to the laboratory approximately $30 \mathrm{~min}$ before conditioning was initiated. The rats were removed from their home cages and placed inside a standard fear conditioning box $(25.5 \times 30 \times 29 \mathrm{~cm}$; Coulbourn Instruments; Allentown, PA) which was inside a separate larger sound attenuation chamber. The conditioning box consisted of aluminum sides, an aluminum ceiling, and a Plexiglas front and back covered with black plastic. The floor consisted of 18 stainless steel rods, spaced $1.25 \mathrm{~cm}$ apart. This box was also the context test apparatus; the cue test apparatus is outlined in the fear association section. After the rats were in the box for $2 \mathrm{~min}$, they were presented with two $10-\mathrm{sec}, 74-\mathrm{dB}, 2500-\mathrm{Hz}$ tones, separated by a 40 -sec inter-stimulus interval. Thus, total exposure of the rats to the box lasted for $3 \mathrm{~min}$.

As illustrated in Figure 1, there were six groups in this experiment (8 rats/group). In two groups of rats each tone presented during conditioning co-terminated with a 2-sec, $0.4 \mathrm{~mA}$ foot shock. In the remaining four groups, no foot shock was delivered. For two immobilization groups, immediately with the termination of the training trial, shocked rats (Shock/Cat/Immobilization) and non-shocked rats (No Shock/Cat/Immobilization) were immobilized using plastic Decapi Cones (Braintree Scientific; Braintree, MA). Within 2 min of being immobilized, rats in these two groups were brought to the cat housing room in the vivarium and were then placed individually in a triangle-shaped wedge $(20 \times 20 \times 10 \mathrm{~cm})$ within a pie-shaped Plexiglas enclosure (Braintree Scientific; 46 $\mathrm{cm}$ diameter $\times 8 \mathrm{~cm}$ height), which was then placed in a metal cage $(61 \times 53 \times 51 \mathrm{~cm})$ with an adult female cat for $30 \mathrm{~min}$. In addition to these groups, one group of shocked rats (Shock Only) and one group of non-shocked rats (Box Only) were immediately returned to their home cages following the conditioning trial. Another non-shocked group (Immobilization Only) was immediately immobilized in plastic DecapiCones upon completion of the conditioning session. After being immobilized, the rats were placed in the pie-shaped Plexiglas enclosure described above in a room other than the cat housing room, where they remained for $30 \mathrm{~min}$. The last non-shocked group (Cat Only) was placed in a small, unrestrictive, novel Plexiglas box $(28 \times 9 \times 14 \mathrm{~cm})$ after conditioning. Within $2 \mathrm{~min}$ of being put in the box, the rats were placed in a metal cage $(61 \times 53 \times 51 \mathrm{~cm})$ with an adult female cat for $30 \mathrm{~min}$. In each group exposed to a cat, canned cat food was smeared on top of the Plexiglas enclosure to direct the cat's attention toward the rats. 
Timeline and General Procedures

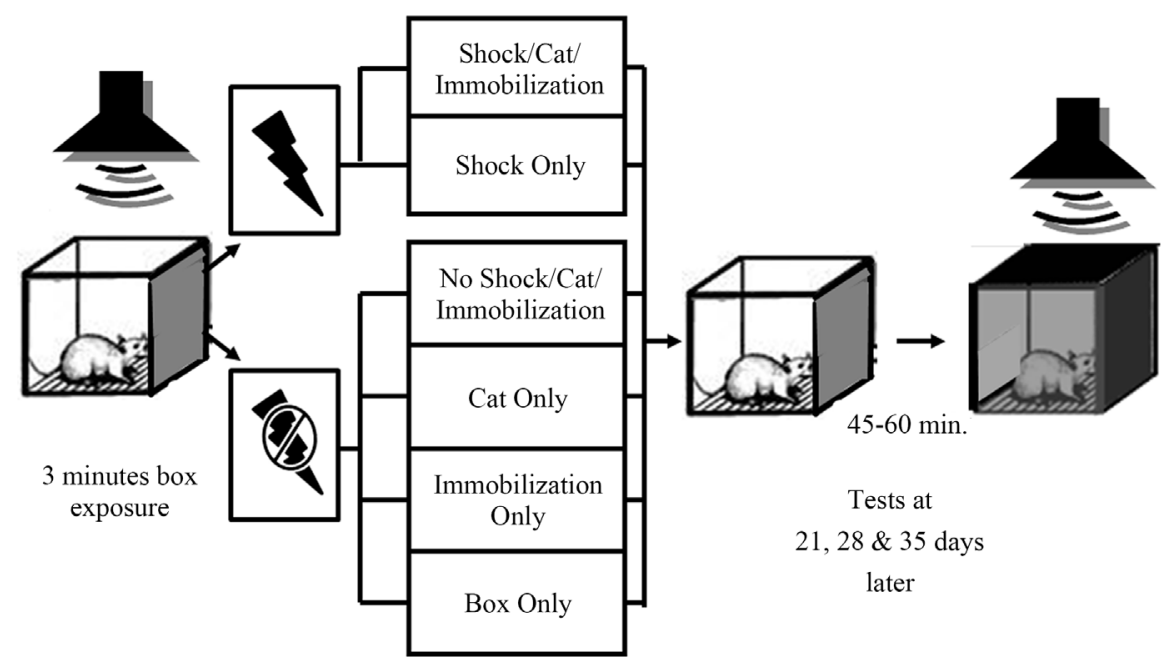

Figure 1. All groups were given 3 min of exposure to the conditioning chamber with 2 tones presented to the rats. Two of the groups received shocks paired with the tones (as illustrated by the lightning bolt symbol). The other 4 groups were not shocked (indicated by the "no" symbol through the lightning bolt). All of the groups received memory tests consisting of unreinforced re-exposure to the conditioning context and, in a different apparatus (indicated as the shaded box), the tone 21, 28 \& 35 days after conditioning.

Fear Memory and Extinction Testing. Context and cued fear memory tests occurred 21, 28 and 35 days after conditioning. These time points were chosen to test long-term memory for the conditioning to potentially model intrusive traumatic memories that occur at great delays following a traumatic experience. On fear memory assessment days, the rats were returned to the laboratory and then tested 30 min later. Rats were placed in the same fear conditioning box as the one in which they were placed during conditioning. The immobility of each rat was monitored by computer for five minutes. Immobility data were analyzed using the time window after the first 30 sec until the beginning of the last minute of the 5 -min chamber exposure. Thus, a total of 3.5 min were analyzed for immobility in the context. This served as a measure for contextual fear memory. Approximately 45 - 60 min after the contextual memory test, rats were individually placed in a novel, illuminated conditioning box $(25 \times 22.5 \times 33 \mathrm{~cm}$, Coulbourn Instruments; Allentown, PA) that consisted of two aluminum sides, an aluminum ceiling, and a Plexiglas front and back and a square metal floor $(21.5 \times 21.5 \mathrm{~cm})$. The use of this second box reduced the similarities between the original conditioning chamber and the auditory cue testing box. The tone (74 $\mathrm{dB} ; 2500 \mathrm{~Hz}$ ) used during training was presented for the last 3 min of a 6-min test. Immobility during each assessment was measured by 24-cell infrared activity monitors (Coulbourn Instruments; Allentown, PA), mounted on the top of the boxes. Freezing was defined as continuous periods of immobility lasting at least $3 \mathrm{sec}$. A Microsoft Excel macro designed to analyze the percent time freezing calculated the total number of seconds spent freezing by each animal in 30-sec epochs.

Statistical Analyses. Mixed-model ANOVAs were used to detect significant differences between groups in freezing to the context and cue tests, with group serving as the between-subjects factor and test day serving as the within-subjects factor. Post hoc LSDs were employed when the omnibus $F$ test indicated the presence of significant effects. Alpha was set at 0.05 for all analyses, and data points were considered outliers if they were more than 3 standard deviations from the exclusive means.

\subsection{Results and Discussion}

Context Memory and Extinction. The analysis of freezing during the context tests revealed a significant effect of group, $F(5,42)=13.18, p<0.01$, with borderline significance for the Group $\times$ Test Day interaction, $F(10$, $84)=1.82, p=0.07$. Across all test days, the Shock/Cat/Immobilization group froze significantly more than all other groups and the Shock Only group and No Shock/Cat/Immobilization group froze significantly more than the Cat, Immobilization and Box Only groups (see Figure 2). During the second context test, the Shock/Cat/ 
Context

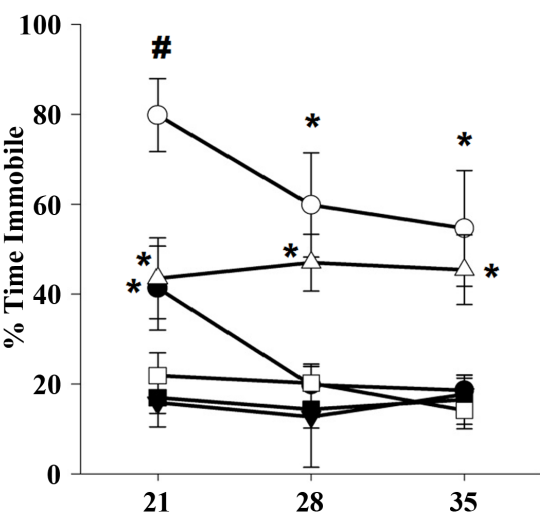

Cue

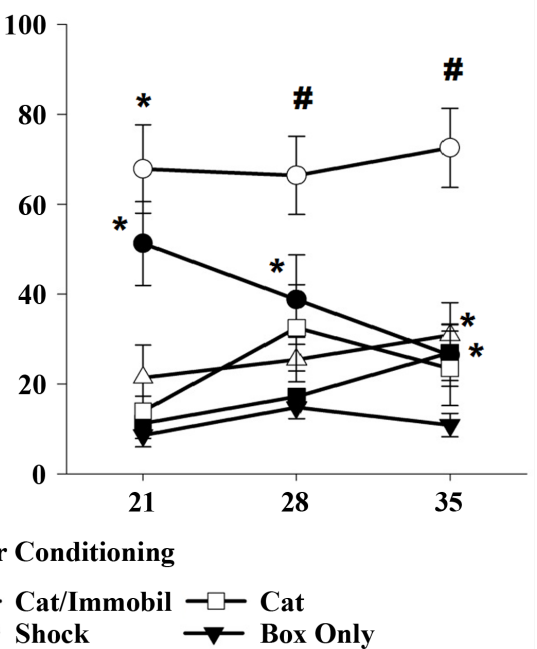

Figure 2. The left graph shows that the group receiving the combination of shock, cat and immobilization exhibited greater freezing in the context than any other group 21 days after conditioning. The no shock/cat/immobilization group also exhibited freezing to the context equivalent to the shock only group. Both the no shock/cat/immobilization and shock only groups spent significantly more time freezing in the context compared to cat, immobilization and box only groups 21 days after conditioning. The shock only group extinguished its freezing to the context, as indicated by reduced freezing on Days 28 and 35. Both the shock and no shock cat/immobilization groups maintained statistically equivalent freezing percentages on days 28 and 35 relative to their initial memory test. The right graph shows that the groups that received shocks spent more time freezing to the tone than groups that were not shocked, but only the group that was shocked, cat exposed and immobilized expressed extinction resistant freezing to the tone. "indicates $p<0.05$ vs. all other groups, ${ }^{*}$ indicates $p<0.05$ vs. box only group.

Immobilization and No Shock/Cat/Immobilization groups froze significantly more than the Shock, Cat, Immobilization and Box Only groups. The third context test revealed that the Shock/Cat/Immobilization and No Shock/ Cat/Immobilization groups froze significantly more than the Shock, Cat, Immobilization and Box Only groups.

Cue Memory and Extinction. The analysis of freezing during the cue tests revealed a significant effect of group, $F(5,39)=12.84, p<0.01$, and a significant Group $\times$ Test Day interaction, $F(2,81)=2.36, p<0.05$. During the first cue test, the Shock/Cat/Immobilization and Shock Only groups froze significantly more during the tone than all other groups. During the second and third cue tests, the Shock/Cat/Immobilization group froze significantly more during the tone than all other groups. The Box Only group spent significantly less time freezing during the tone than the No Shock/Cat/Immobilization group, which was statistically equivalent to the Cat Only and Immobilization Only groups.

This experiment examined how three aversive stimuli, used alone or in various combinations, impacted memory. There are three novel findings from this experiment. First, the combination of immobilization with predator exposure in conjunction with standard foot shock conditioning produced greater persistence and magnitude of conditioned contextual and cued fear memory than any of these reinforcers delivered in isolation. The second finding is that the combination of immobilization, cat and shock produced a fear conditioned memory, for both context and cue, which was resistant to extinction, tested at weekly intervals from 3 - 5 weeks after conditioning. The third finding is that the combination of immobilization and predator exposure, in the absence of a standard foot shock US, produced intact contextual, but not cue, fear conditioning which was resistant to extinction training. Finally, immobilization or predator exposure, alone, resulted in a similar pattern to the Box Only group, which was the absence of an expression of fear memory 3 weeks post-conditioning.

One feature that is unique in this experiment is the considerable trace interval (approximately 2 minutes) between context exposure and immobilization to predator exposure, and yet the combination produced robust and extinction-resistant fear. Long trace intervals (more than $30 \mathrm{sec}$ ) reduce the associative qualities in Pavlovian conditioning [81] [82]. It is likely that the use of immobilization immediately after removal of the rats from the shock chamber was sufficiently strong reinforcement to bridge the 2 minute trace period between removal of the rat from the context and cat exposure. The relatively long trace period between the time that the rat was removed 
from the conditioning box and placed in the presence of the cat (2 min without immobilization) is a likely explanation for the lack of conditioned freezing in the cat only group.

Overall, the results of this experiment indicate that immobilization combined with predator exposure and foot shock produced a powerful synergistic effect on fear memory which was resistant to extinction assessed with 3 weekly exposures to the training context and cue from $3-5$ weeks post-conditioning. It therefore appears the combination of all three reinforcers may serve as the most effective stimulus to model the pathologically intense and extinction-resistant memories which are a hallmark feature of PTSD and related disorders [83] [84].

\section{Experiment 2}

Shapiro \& Eichenbaum [85] hypothesized that the capacity of the hippocampus to receive and integrate information from different senses allows the hippocampus to generate a coherent representation of the context through the associations made between the information. Thus, the hippocampus is important for acquiring new declarative memories [86] [87] which can be either emotional or neutral in nature. In laboratory animals, damage to the hippocampus seven days before contextual learning [31] or muscarinic cholinergic receptor antagonism of the hippocampus fifteen minutes prior to learning [88] impairs performance on contextual fear conditioning. Rogers, Hunsaker, \& Kesner [89] demonstrated that chemical lesions of the dorsal CA1 area of the hippocampus led to significantly less freezing in the conditioned context, yet the lesions did not significantly impair trace auditory cue conditioning. More recent work employing selective optogenetic manipulation of hippocampal cell activity has confirmed the role of the hippocampus in contextual fear conditioned memory [24] [25] [36]-[38]. Based on these findings, experiment 2 tested the hypothesis that inactivation of the hippocampus would result in impaired context, but not cue, predator-based fear expression.

\subsection{Method}

Design. We employed a $2 \times 2$ factorial design, with drug [vehicle (aCSF) or muscimol] and group [immobilization with cat exposure (Cat) or home cage (No Cat)] serving as the factors.

Animals and Surgery. A total of 38 male Sprague-Dawley rats (Charles River Laboratories) were used in this experiment and all aspects of care, age and weight were identical to those in Experiment 1 . On the day of surgery, the rats were brought to the laboratory, where all surgical procedures were performed under aseptic conditions. Rats were deeply anesthetized using isoflurane. Their heads were shaved and then placed level in a stereotaxic device. After the skull was exposed, the topographical coordinates for the landmarks of bregma and lambda were recorded for targeting purposes. The target was the dorsal CA1 region of the hippocampus (coordinates, in reference to bregma: $-3.8 \mathrm{~mm}$ AP, $\pm 3.0 \mathrm{~L},-2.8 \mathrm{DV}$ ) and insertions were made with 26-gauge, stainless steel, guide cannula (Plastics One Inc., Roanoke, VA). Guide cannula were held in place by dental cement and anchored to the skull with four skull screws. Removable stylets projecting $1 \mathrm{~mm}$ from the tip of the guide cannula were inserted and held in place with a screw-on dust cap (Plastics One Inc., Roanoke, VA) to keep the cannula patent.

Intracerebral Infusions. All animals were given one week to recuperate from surgery before data collection. All infusion and behavioral procedures were performed between 900 - 1500 hours, and animals were tested on three consecutive days. On the first day, the dust cap was removed, and a mock injection tube was placed on the cannula pedestal. The second and third days consisted of removing the dust cap and stylet and gently placing the injectors (Plastics One) into the guide cannula. A Harvard Apparatus pump (Holliston, MA), connected to 25- $\mu 1$ syringe injectors (Hamilton) by plastic tubing (Plastics One), infused aCSF at a rate of $0.1 \mu \mathrm{l} / \mathrm{min}$ for $3 \mathrm{~min}$ on Day 2 (based on a pilot study optimizing flow rate and dose). After the infusion, the pump was turned off and the fluid was given 1 min to diffuse before the dummy cannula was replaced and dust cap was screwed back on the top of the pedestal. On the third day, aCSF or muscimol $(1 \mu \mathrm{g} / \mu \mathrm{l}$ dissolved in aCSF, a total of $0.3 \mu \mathrm{g}$ per infusion site) was administered; these infusion procedures were derived from Holt \& Maren [90] and modified based on pilot testing results.

Histology. A total of 36 rats completed testing. Upon completing the behavioral tasks, all animals were euthanized with an overdose of ketamine and xylaxine, and cresyl violet was infused into the cannula at a rate of $0.1 \mu \mathrm{l} / \mathrm{min}$ for $5 \mathrm{~min}$ to allow visual inspection of cannula placement. The brains were extracted and flash frozen in methylbutane, and the tissue was stored at $-80^{\circ} \mathrm{C}$ until it was sliced in coronal sections in $40-\mu \mathrm{m}$ increments on a Cryostat held at $-16^{\circ} \mathrm{C}$ and mounted on microscope slides. There were 2 animals excluded from analysis 
for cannula placement outside of the target area.

Cat Exposure Procedure. Approximately 15 min after the rats were infused with aCSF or muscimol on Day 3, they were placed in a fear conditioning chamber (as described in Experiment 1). Exposure to the chamber for 3 min terminated with the presentation of a single $30-\mathrm{sec}, 74-\mathrm{dB}, 2500-\mathrm{Hz}$ tone, which served as the auditory cue. Animals in the Cat groups were immediately immobilized and then placed in close proximity to a cat and remained with the cat for $1 \mathrm{hr}$. Animals in No Cat groups were returned to their home cages. Three weeks later context and cue memory tests were conducted as described in experiment 1 , but extinction memory was not tested.

Statistical Analyses. Data were analyzed with 2-way ANOVAs. A priori planned comparisons were tested with two-tailed Student's $t$-tests in each behavioral test of the experiment. Alpha was set at 0.05 for all analyses.

\subsection{Results and Discussion}

Context Memory. There were significant effects of group, $F(1,28)=4.46, p<0.05$, and drug, $F(1,28)=5.95$, $p<0.05$, but the Group $\times$ Drug interaction was not significant, $F(1,28)=1.34, p=0.26$. Planned comparisons showed that muscimol infused prior to the cat procedure significantly reduced $(p<0.03)$ freezing compared to aCSF (Figure 3).

Cue Memory. There was a significant effect of group, $F(1,29)=9.69, p<0.01$, but the effect of drug, $F(1$, $29)=0.35, p>0.05$, and Group $\times$ Drug interaction, $F(1,29)=0.64, p>0.05$, were not significant. Cat exposure resulted in animals freezing more to the cue, relative to the No Cat groups (Figure 4).

In this experiment, the role of the dorsal CA1 region of the hippocampus in Pavlovian predator-based contextual and cued fear conditioning was investigated. Previous work has shown that lesions or inactivation of the dorsal hippocampus prior to foot shock conditioning block the expression of contextual, but not cued, fear memory [23] [30]-[34]. The present experiment demonstrates that the dorsal hippocampus is necessary for predator-based context fear memory. Thus, there is aselective involvement of the hippocampus in contextual, but not cue, fear conditioning in our predator-based fear conditioned paradigm, as it is in conventional paradigms utilizing foot shock.

Pentkowski, Blanchard, Lever, Litvin, \& Blanchard [91] presented results that implicated the ventral, but not dorsal, hippocampus in unconditioned and conditioned defensive responses. The results of their experiment suggest that the inactivation of the dorsal CA1 would not significantly affect behavior. However, the lesions in Pentkowski et al. [91] were made one week before behavioral testing and previous studies indicate that other brain structures can compensate for memory affected by dorsal hippocampal damage [29]. The results of Experiment 2 support the hypothesis that the dorsal CA1 area of the hippocampus plays a vital role in the conditioned contextual, but not auditory cue-based, associations formed during predator-based conditioning.

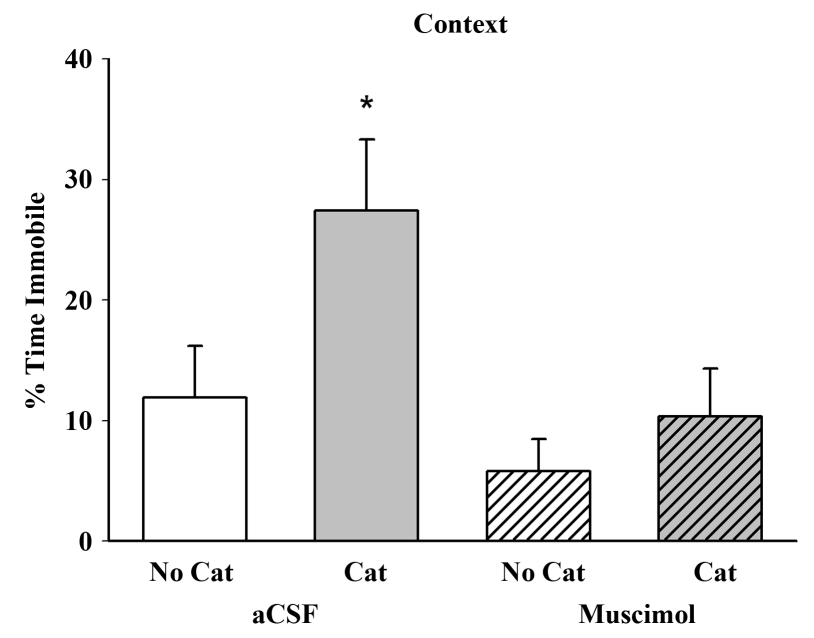

Figure 3. The aCSF-CAT group froze significantly more than the Muscimol-Cat group. Muscimol application to the dorsal CA1 area of the hippocampus blocked contextual memory in the cat-exposed group compared to the cat group administered aCSF. ${ }^{*}$ indicates $p<0.05$ vs. all other groups. 
Cue

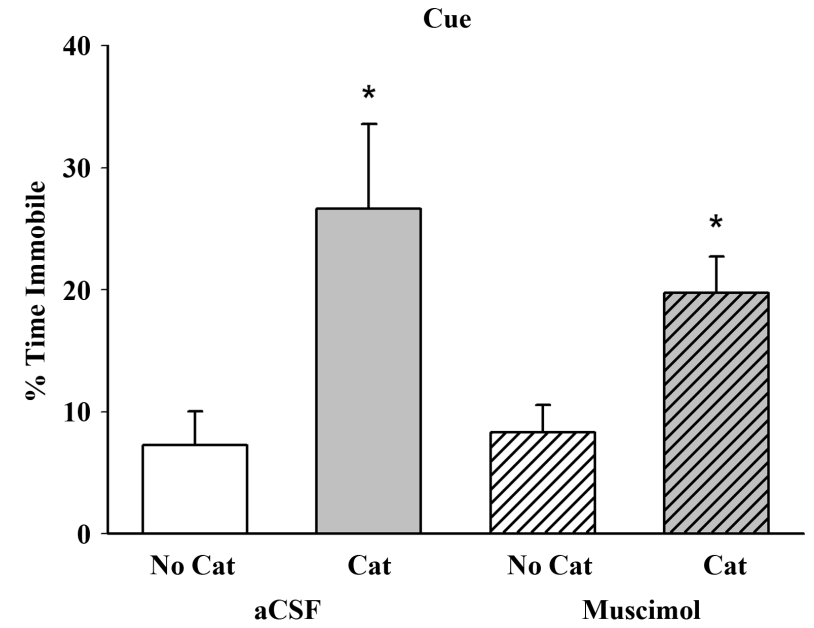

Figure 4. Predator exposure and immobilization resulted in significantly greater freezing to the tone than the no cat groups. Muscimol administration to the dorsal CA1 area of the hippocampus did not block the cued freezing in the cat-exposed group. ${ }^{*}$ indicates $p<0.05$ vs. respective no cat groups.

\section{Experiment 3}

Sleep loss is associated with negative impacts on mood, motor function, and cognitive performance [92]. Sleep deprivation (SD) is mentally and physically stressful [93] and impairs cognitive functioning [94]-[99]. In humans, chronic mild sleep restriction, of 2 - 6 hours of sleep per night, and complete acute SD impair cognitive performance compared to non-sleep deprived individuals [100].

The cognitive impairments associated with SD are found in episodic and declarative memory, two forms of memory that involve hippocampal function. Research using rodent models indicates that SD interferes with learning and memory associated with the hippocampus. For example, contextual (hippocampus-dependent), but not cued (hippocampus-independent), fear conditioning is impaired in SD rats [101]-[104]. These findings indicate that SD targets hippocampus-dependent processing. We therefore tested the hypothesis that sleep deprivation would impair hippocampus-dependent contextual, but not amygdala-mediated cue, fear memory. Specifically, we hypothesized that $24 \mathrm{hr}$ SD prior to predator-based fear conditioning would impair contextual fear, while sparing auditory cue fear memory.

\subsection{Method}

Animals and Sleep Deprivation. A total of 44 male Sprague-Dawley rats (Charles River Laboratories) were used in this experiment and all aspects of care, age and weight were identical to those in Experiments 1 and 2. The rats were randomly assigned to receive sleep deprivation (SD) or no sleep deprivation (NSD). Standard Plexiglas cages were modified to accommodate the flower pot technique and allow the availability of food and water throughout the $24 \mathrm{hr}$ before conditioning [105]. The SD cages had a vertical extension such that when 4 platforms (polypropylene jars, PCG Scientific, $9 \mathrm{~cm}$ high $\times 6 \mathrm{~cm}$ diameter) were placed in the cage, rats could move freely and access food and water from the standard wire lid. The cages were filled with room temperature tap water raised to within $1 \mathrm{~cm}$ of the top of the platforms. The NSD rats were housed in Standard Plexiglas cages for $24 \mathrm{hr}$ prior to conditioning in same room that the SD procedure took place. All rats were continually housed with their regular cage mates throughout the $24 \mathrm{hr}$ prior to conditioning.

Fear Conditioning. The same conditioning apparatus used in Experiments 1 and 2 were utilized. Rats were randomly assigned to receive immobilization and predator exposure (Cat) or home cage (No Stress). Rats were placed in the conditioning chambers and allowed 3 min to explore the context. During the last 30 sec of conditioning a $74-\mathrm{dB}, 2500-\mathrm{Hz}$ auditory tone was presented. Immediately after the cessation of the tone, rats in the Cat groups were immobilized and placed in the presence of a cat (as described in Experiment 1 ) for 10 min. After the $10 \mathrm{~min}$ in the presence of the cat, rats were placed either in their home cage or in the SD apparatus for 25 min before another identical conditioning trial occurred. This was repeated for a total of 3 conditioning trials. Testing for contextual and cued fear, as previously described, was performed $72 \mathrm{hr}$ after conditioning. 
Analyses. Separate 2-way ANOVAs were used to detect differences in freezing behavior in response to the context, novel environment and cue. SD and Cat served as the between-subjects factors for these analyses. Alpha was set at 0.05 for all analyses.

\subsection{Results and Discussion}

Context Memory. There were significant effects of SD, $F(1,40)=15.23, p<0.01)$, and Cat, $F(1,40)=9.25, p$ $<0.01)$, and a significant SD $\times$ Cat interaction, $F(1,40)=9.85, p=0.01$. The NSD-Cat group froze significantly more in the conditioning context than all other groups.

There were no significant differences in freezing behavior in the novel environment. Analyses of the data for freezing to the cue revealed a significant main effect of Cat, $F(1,39)=5.05, p=0.03$. The Cat groups spent significantly more time freezing during the cue than the No Cat groups. The effect of $\mathrm{SD}, F(1,39)=2.69, p=$ 0.11 , and the $\mathrm{SD} \times$ Cat interaction, $F(1,39)=0.60, p=0.81$, were not significant (Figure 5).

This experiment replicated and extended the predator-based Pavlovian fear conditioning paradigm developed in the previous experiments. Sleep deprivation before predator-based fear conditioning impaired contextual fear conditioning as indicated by the significant sleep deprivation and predator stress interaction. Notably, sleep deprivation had no effect on predator-based fear conditioning to the auditory cue. Therefore, these findings support the hypothesis that sleep deprivation is detrimental to contextual (hippocampus-dependent), but not cued (hippocampus-independent), fear conditioning [101]-[104]. The findings further suggest a commonality of mechanisms of adverse effects of sleep deprivation on shock and predator-based contextual fear conditioning, such as a diminished glucocorticoid response and a reduction of the phosphorylation of the transcription factor 3',5'-cyclic AMP response-element binding protein (CREB) [106].

\section{General Discussion}

The use of a live cat or cat odor to produce a strong innate fear reaction, as well as conditioned fear memory, in rats has been documented by numerous laboratories (for reviews see [41] [55] [67] [68] [107]-[111]). In the current work we assessed the magnitude and extinction of a rat's fear conditioned memory of a live predator (cat), alone and in combination with immobilization and foot shock. In Experiment 1 we found that either cat exposure or immobilization, in isolation, was ineffective as an unconditioned stimulus. In contrast, the combination of immobilization and predator exposure generated a long-lasting ( 3 - 5 week) contextual fear memory. The combination of all three reinforcers (cat exposure, immobilization and foot shock) produced the greatest magnitude and persistence of fear conditioned memory, as well as resistance to extinction, for both context and cue. In Experiment 2 we focused on the role of the hippocampus in predator-based fear memory. Pharmacological inactivation of the hippocampus produced a selective blockade of contextual, but not cued, fear conditioning. Experiment 3 extended the predator-based fear conditioning paradigm further by assessing the effects of sleep deprivation

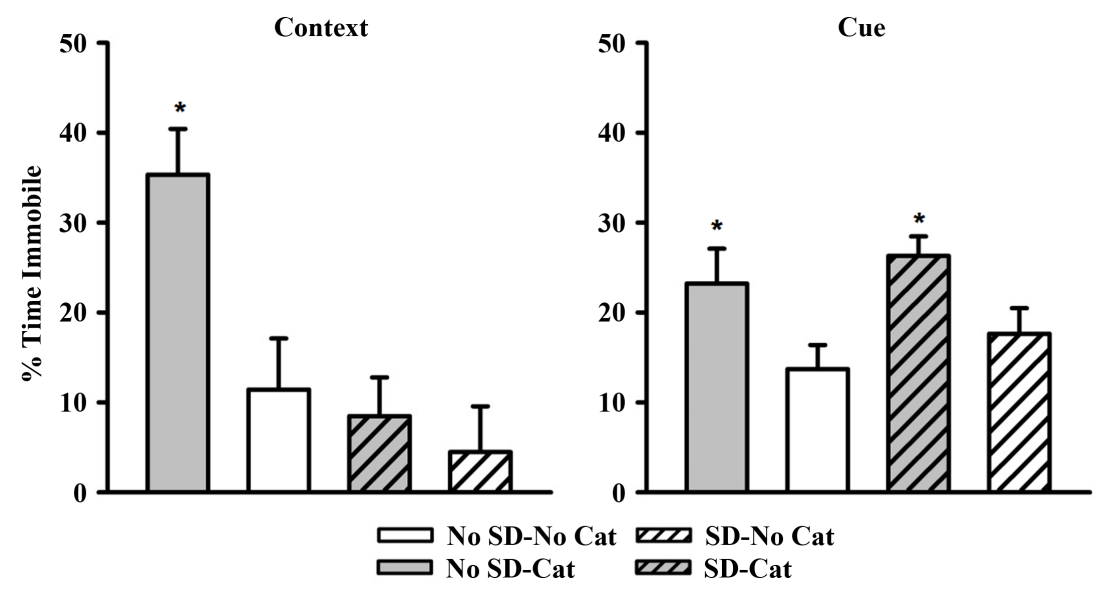

Figure 5. Sleep deprivation (SD) significantly reduced freezing to the context (hippocampal-dependent) aspect of predator based memory tested $72 \mathrm{hr}$ after conditioning (left). Freezing to the auditory cue was not significantly affected by sleep deprivation (right). ${ }^{*}$ indicates $p<0.05$. 
prior to fear conditioning on fear memory expression. This approach provided an effect which was equivalent to inactivation of the hippocampus, with the selective impairment of the expression of contextual, but not cued, fear memory.

One explanation for the findings in Experiment 1 is that the expression of conditioned fear is expressed as a function of the magnitude on the intensity of the aversive stimulus. That is, presenting different US stimuli (shock, cat and immobilization) as a combined US is analogous to increasing the intensity of shock in conventional fear conditioning to produce a greater magnitude of fear conditioned memory [112] [113]. Thus, the multiple types of aversive stimuli administered during fear conditioning could account for the more robust memory we observed. From this perspective, the predator or immobilization manipulations, alone, were insufficiently intense to reach a hypothetical threshold necessary to form the fear association, just as very low shock intensities do not produce fear conditioning [114]. In theory, the combination of immobilization and predator exposure was sufficiently intense to reach the conditioning threshold. The intensity of the stimulus interpretation also accounts for the augmented memory in the group that received all three aversive stimuli.

An alternative interpretation of a subset of the findings in Experiment 1 is that cat exposure, alone, was ineffective at producing a fear-conditioned memory because the 2 minute delay period between removal of the rat from the chamber and exposure to the cat was an excessively long trace period between the CS and US. Long trace intervals (more than $30 \mathrm{sec}$ ) reduce the associative qualities in Pavlovian conditioning [81] [82]. Therefore, immobilization immediately after removal of the rats from the shock chamber may have served as a partial US to bridge the trace period between removal of the rat from the explicit CS (chamber) and US (immobilization and cat exposure). Additional work employing immobilization only during the 2 minute trace period may be of value to determine whether immobilization can serve solely to link the CS with the cat as the US.

It is important to note that unlike conventional classical conditioning training, in the current work involving only immobilization and cat exposure as the combined US, the CS (context/cue) and US (immobilization during cat exposure) occurred in completely different locations. That is, in traditional classical conditioning, the CS and US are always presented together in the same context. For example, in typical fear conditioning training, rats are administered foot shock and a tone in the same context [115] [116]. A rat's memory for the shock is then tested by observing the rat's behavior when it is returned to the same environment where the shock occurred. We have shown here that rats can associate two neutral stimuli (CSs; chamber and tone) with an aversive experience (US; immobilization during predator exposure) that occurred in two different places. That is, the rats were removed from the chamber and brought to another room, where cat exposure occurred, and yet, the rats exhibited fear when they were returned to the chamber or exposed to the tone. Thus, our demonstration that rats can associate cues that occurred across time and space may be relevant toward understanding how traumatic stress can produce context-independent intrusive memories in people [117]-[120].

When all three reinforcers were delivered in conjunction, i.e., shock in the chamber followed by immobilization and cat exposure outside the chamber, the fear conditioned memory exhibited its greatest magnitude, persistence and resistance to extinction. Thus, multiple aversive stimuli in one training session amplified the potency of context and cued fear memory. Related work has demonstrated that the use of a single (2 hour) restraint stress session 2 days prior to fear conditioning enhanced contextual freezing, but not freezing to an auditory cue [121]. In addition, research on stress (shock) prior to fear conditioning enhanced the expression of fear memory [122]-[124]. Our work is novel in that qualitatively different reinforcers generated a form of fear memory which was expressed 3 weeks after the conditioning session, which continued to be expressed following 3 weekly extinction sessions. This approach may serve as a global model for the great persistence and resistance to extinction in people with PTSD [83] [84] [125]

In related work, Corley et al. [126] demonstrated augmented foot shock conditioning with the use of predator odor. The design of their experiments involved shocking the rats in one context (acute stress) and then placing them in a standard housing cage and exposing them to an auditory cue (clicking noises). While in the standard housing cage, a predator-odor laden cloth was placed on top of the cage for 30 sec midway through the auditory conditioning; this procedure was repeated for a total of 5 training trials. To test extinction of conditioned fear, the rats were placed in a "runway with hide box" and re-exposed to the auditory cues for 5 consecutive days. The results of their experiments demonstrated that stress-induced fear conditioning led to persistent freezing to the cue over the 5 days of testing in the runway-hide box. Their work demonstrates the great value in the use of heterogeneous and ethologically relevant reinforcers in the assessment of fear learning.

In other related work, Cohen and colleagues [127]-[130] incorporated a fear conditioning-like component into 
their animal model of PTSD. These investigators exposed rats to well-soiled cat litter (predator scent stress) and subsequently measured their freezing behavior in response to fresh, unused cat litter. They found that predator scent stress-exposed rats exhibited significant freezing behavior upon exposure to unused cat litter, which suggested that the rats had a fear-provoking memory of the predator scent stress experience. Their work provides insight into how a fear-provoking experience produces a long-term change in rat behavior. However, their approach did not provide conclusive evidence that the stressed rats had formed an explicit association between a previously neutral cue (CS) and a biologically relevant, arousing stimulus (US), which is an essential feature of classical conditioning [131]. The increased freezing their stressed rats exhibited in response to clean litter may have developed as a result of increased generalized fear to all novel stimuli. Thus, the possibility that the predator scent stress experience produced a non-associative sensitization of stress responses was not addressed in their work.

As with work from other laboratories using predators, or predator-related stimuli, the fear-based associations we have demonstrated here are likely to involve conjoint amygdala and hippocampal processing [22] [126] [132]. However, it is noteworthy to consider that additional brain structures are likely to have been involved in predator-specific based memory processing. Specifically, Canteras and co-workers have demonstrated that subnuclei in the amygdala, thalamus, periaqueductal grey and hypothalamus are responsive to sensory, as well as memory-specific processing of predator cues [22] [53] [56]-[58]. In theory, these nuclei not only contribute to sensory-specific cue responses, they may have also contributed to the powerful augmentation of fear conditioned memory and the resistance to extinction we observed when cat exposure was combined with immobilization and shock.

Experiment 2 investigated the role of the dorsal CA1 region of the hippocampus in predator-based contextual and cued fear conditioning. The CA1 region of the hippocampus theoretically is integral to memory because it receives input from various modalities and outputs to the cortex [133]-[136]. Moreover, CA1 has been shown to be activated during fear conditioning [137]-[139], is important for contextual fear memory formation [140] and optogenetic inhibition of CA1 impairs contextual fear memory retrieval [141]. Therefore, Experiment 2 tested the hypothesis that a transient inactivation of the dorsal CA1 region of the hippocampus would selectively block contextual, but not cued, fear memory formation and expression. This experiment demonstrated that, just as in foot shock conditioning paradigms, the predator-based context, but not cue, fear memory is dependent on a functioning CA1 region of the hippocampus.

Finally, Experiment 3 provided support for the hypothesis that sleep deprivation would impair hippocampus-dependent contextual, but not amygdala-mediated cue, fear memory. This finding is consistent with other work that demonstrates that sleep deprivation targets contextual, but not cued, fear memory with shock as reinforcement [101] [104] [106] [142].

The observations on sleep deprivation and fear conditioning are relevant to clinical research which demonstrates that sleep disturbances immediately prior to a traumatic event are associated with an increase in the risk of psychiatric disorders [143]. In their meta-analysis, Bryant et al. [143] pointed out that sleep disturbance predicted clinical disorders, such as PTSD and major depression, better than age, gender, severity of trauma and previous psychiatric disturbances. The authors acknowledged that there are likely common underpinnings for the relationship among the disorders; however, they recognized that there could be disorder-specific mechanisms posed by sleep disturbances prior to trauma. One explanation proposed for their finding is that sleep impairment reduces emotional, cognitive, and physical resources that would otherwise mitigate the aftermath of trauma exposure. Fatigue, a common outcome with impaired sleep [144], produces cognitive impairment, such as reduced attention and concentration [145]. Thus, individuals who are deprived of sleep and have depleted capacity to deal with trauma could develop the type of fragmented, dissociative memories that are common with trauma [125].

The ability to appraise events in a larger social and contextual network, along with heightened prefrontal cortex functioning, could buffer a traumatized person against the development of clinical disorders, such as PTSD [67] [146]. The buffering mechanisms, however, are reduced by sleep deprivation, thereby rendering sleepdeprived traumatized individuals prone to the development of PTSD [93] [147] [148].

The clinical disorders implicated in these studies have been theorized to involve the amygdala [149]. This line of research would suggest that an interaction between sleep deprivation and trauma would enhance amygdala processing and, by extension, auditory fear conditioning. Evidence from fMRI studies of increased amygdala activation and reduced amygdala-PFC functional connectivity as a result of sleep deprivation suggest that indi- 
viduals are less able to adapt to trauma after sleep deprivation than non-sleep-deprived individuals [150].

One hypothesis addressing stress-induced insomnia posits that hyperarousal is at the core of the inability to sleep [151]. Therefore, sleep deprivation before trauma could add to the magnitude of fear conditioning. However, the findings of the current study do not support this hypothesis. Fear conditioning to an auditory cue occurred as a result of the predator-based stimulus, as indicated by the significant main effect of cat exposure. However, the magnitude of the cued fear memory expression was no greater in sleep-deprived animals than in non-sleep deprived animals. Nevertheless, an imbalance of the fear memory with a bias towards a representation in the amygdala without a hippocampal representation may be expressed as an abnormal, fragmented, and perhaps excessively intrusive memory trauma [125]. Research on traumatized people with brain imaging may resolve the issue of a putative imbalance between hippocampal and amygdala representation of trauma as the basis of intrusive memories.

\section{Conclusion}

In summary, this series of experiments centered on a predator-based fear conditioning paradigm provides a model for studying the neurobiology of fear memory with an ethologically relevant reinforcer. The findings indicate that predator-based fear conditioning and extinction involve an overlap of neural structures involved in conventional foot shock-based fear conditioning, as in the distinction between hippocampal (contextual) and amygdaloid (cue-based) fear conditioning. However, life-threatening stimuli appear to activate a unique neural circuitry in rodents [55], and perhaps in humans, as well [152]. Therefore, the hybrid approach of utilizing shock- with predator-based fear conditioning may provide the ideal approach toward modeling the neurobiology of traumatic memory, as well as in developing more effective pharmacotherapy for PTSD.

\section{Acknowledgements}

This research was supported by Career Scientist and Merit Review Awards from the Biomedical Laboratory Research \& Development Service of the Department of Veterans Affairs to David Diamond. The opinions expressed in this paper are those of the authors and not of the Department of Veterans Affairs or the US government.

\section{References}

[1] Blanchard, R.J., McKittrick, C.R. and Blanchard, D.C. (2001) Animal Models of Social Stress: Effects on Behavior and Brain Neurochemical Systems. Physiology \& Behavior, 73, 261-271. http://dx.doi.org/10.1016/S0031-9384(01)00449-8

[2] Diamond, D.M. and Zoladz, P.R. (2016) Dysfunctional or Hyperfunctional? The Amygdala in Posttraumatic Stress Disorder Is the Bull in the Evolutionary China Shop. Journal of Neuroscience Research, 94, 437-444. http://dx.doi.org/10.1002/jnr.23684

[3] Fanselow, M.S. (1994) Neural Organization of the Defensive Behavior System Responsible for Fear. Psychonomic Bulletin \& Review, 1, 429-438. http://dx.doi.org/10.3758/BF03210947

[4] Maren, S. (2001) Neurobiology of Pavlovian Fear Conditioning. Annual Review of Neuroscience, 24, 897-931. http://dx.doi.org/10.1146/annurev.neuro.24.1.897

[5] Kim, J. and Jung, M. (2006) Neural Cicuits and Mechanisms Involved in Pavlovian Fear Conditioning: A Critical Review. Neuroscience \& Biobehavioral Reviews, 30, 188-202. http://dx.doi.org/10.1016/j.neubiorev.2005.06.005

[6] Walters, E.T., Carew, T.J. and Kandel, E.R. (1979) Classical Conditioning in Aplysiacalifornica. Proceedings of the National Academy of Sciences of the United States of America, 76, 6675-6679. http://dx.doi.org/10.1073/pnas.76.12.6675

[7] Walters, T. and Kandel, E.R. (1981) Classical Conditioning a Simple Withdrawal Reflex in Aplysia. Journal of Neuroscience, 1, 1426-1473.

[8] Holahan, M.R. and White, N.M. (2002) Conditioned Memory Modulation, Freezing, and Avoidance as Measures of Amygdala-Mediated Conditioned Fear. Neurobiology of Learning and Memory, 77, 250-275. http://dx.doi.org/10.1006/nlme.2001.4012

[9] Sehlmeyer, C., Schöning, S., Zwitserlood, P., Pfleiderer, B., Kircher, T., Arolt, V. and Konrad, C. (2009) Human Fear Conditioning and Extinction in Neuroimaging: A Systematic Review. PloS One, 4, e5865.

http://dx.doi.org/10.1371/journal.pone.0005865 
[10] Curzon, P., Rustay, N.R. and Browman, K.E. (2009) Cued and Contextual Fear Conditioning for Rodents. In: Buccafusco, J.J., Ed., Methods of Behavior Analysis in Neuroscience, CRC Press, Boca Raton, 1-12.

[11] Sears, R.M., Schiff, H.C. and LeDoux, J.E. (2014) Molecular Mechanisms of Threat Learning in the Lateral Nucleus of the Amygdala. Progress in Molecular Biology and Translational Science, 122, 263-304. http://dx.doi.org/10.1016/B978-0-12-420170-5.00010-6

[12] Helmstetter, F.J. and Bellgowan, P.S. (1994) Effects of Muscimol Applied to the Basolateral Amygdala on Acquisition and Expression of Contextual Fear Conditioning in Rats. Behavioral Neuroscience, 108, 1005-1009. http://dx.doi.org/10.1037/0735-7044.108.5.1005

[13] Maren, S. (2008) Pavlovian Fear Conditioning as a Behavioral Assay for Hippocampus and Amygdala Function: Cautions and Caveats. European Journal of Neuroscience, 28, 1661-1666. http://dx.doi.org/10.1111/j.1460-9568.2008.06485.x

[14] Muller, J., Corodimas, K.P., Fridel, Z. and LeDoux, J.E. (1997) Functional Inactivation of the Lateral and Basal Nuclei of the Amygdala by Muscimol Infusion Prevents Fear Conditioning to an Explicit Conditioned Stimulus and to Contextual Stimuli. Behavioral Neuroscience, 111, 683-691. http://dx.doi.org/10.1037/0735-7044.111.4.683

[15] Pare, D. and Duvarci, S. (2012) Amygdala Microcircuits Mediating Fear Expression and Extinction. Current Opinion in Neurobiology, 22, 717-723. http://dx.doi.org/10.1016/j.conb.2012.02.014

[16] Wilensky, A.E., Schafe, G.E. and LeDoux, J.E. (1999) Functional Inactivation of the Amygdala before but Not after Auditory Fear Conditioning Prevents Memory Formation. The Journal of Neuroscience: The Official Journal of the Society for Neuroscience, 19, RC48. http://www.ncbi.nlm.nih.gov/pubmed/10594092

[17] Fanselow, M.S. and Ledoux, J.E. (1999) Why We Think Plasticity Underlying Pavlovian Fear Conditioning Occurs in the Basolateral Amygdala. Neuron, 23, 229-232.

[18] Blanchard, D.C. and Blanchard, R.J. (1972) Innate and Conditioned Reactions to Threat in Rats with Amygdaloid Lesions. Journal of Comparative and Physiological Psychology, 81, 281-290. http://dx.doi.org/10.1037/h0033521

[19] Maren, S. (1998) Overtraining Does Not Mitigate Contextual Fear Conditioning Deficits Produced by Neurotoxic Lesions of the Basolateral Amygdala. The Journal of Neuroscience: The Official Journal of the Society for Neuroscience, 18, 3088-3097. http://www.ncbi.nlm.nih.gov/pubmed/9526025

[20] Maren, S. (1999) Neurotoxic Basolateral Amygdala Lesions Impair Learning and Memory but Not the Performance of Conditional Fear in Rats. The Journal of Neuroscience: The Official Journal of the Society for Neuroscience, 19, 86968703. http://www.ncbi.nlm.nih.gov/pubmed/10493770

[21] Maren, S. and Quirk, G.J. (2004) Neuronal Signalling of Fear Memory. Nature Reviews Neuroscience, 5, 844-852. http://dx.doi.org/10.1038/nrn1535

[22] Martinez, R.C., Carvalho-Netto, E.F., Ribeiro-Barbosa, E.R., Baldo, M.V.C. and Canteras, N.S. (2011) Amygdalar Roles during Exposure to a Live Predator and to a Predator-Associated Context. Neuroscience, 172, 314-328. http://dx.doi.org/10.1016/j.neuroscience.2010.10.033

[23] Phillips, R.G. and LeDoux, J.E. (1992) Differential Contribution of Amygdala and Hippocampus to Cued and Contextual Fear Conditioning. Behavioral Neuroscience, 106, 274-285. http://www.ncbi.nlm.nih.gov/pubmed/1590953 http://dx.doi.org/10.1037/0735-7044.106.2.274

[24] Beyeler, A., Eckhardt, C.A. and Tye, K.M. (2014) Deciphering Memory Function with Optogenetics. Progress in Molecular Biology and Translational Science, 122, 341-390. http://dx.doi.org/10.1016/B978-0-12-420170-5.00012-X

[25] Johansen, J.P., Wolff, S.B., Luthi, A. and LeDoux, J.E. (2012) Controlling the Elements: An Optogenetic Approach to Understanding the Neural Circuits of Fear. Biological Psychiatry, 71, 1053-1060. http://dx.doi.org/10.1016/j.biopsych.2011.10.023

[26] Han, J.H., Kushner, S.A., Yiu, A.P., Hsiang, H.L., Buch, T., Waisman, A., et al. (2009) Selective Erasure of a Fear Memory. Science, 323, 1492-1496. http://dx.doi.org/10.1126/science.1164139

[27] Reijmers, L.G., Perkins, B.L., Matsuo, N. and Mayford, M. (2007) Localization of a Stable Neural Correlate of Associative Memory. Science, 317, 1230-1233. http://dx.doi.org/10.1126/science.1143839

[28] Broadbent, N.J. and Clark, R.E. (2013) Remote Context Fear Conditioning Remains Hippocampus-Dependent Irrespective of Training Protocol, Training-Surgery Interval, Lesion Size, and Lesion Method. Neurobiology of Learning and Memory, 106, 300-308. http://dx.doi.org/10.1016/j.nlm.2013.08.008

[29] Sanders, M. (2003) The Place of the Hippocampus in Fear Conditioning. European Journal of Pharmacology, 463, 217-223. http://dx.doi.org/10.1016/S0014-2999(03)01283-4

[30] Kim, J.J., Rison, R.A. and Fanselow, M.S. (1993) Effects of Amygdala, Hippocampus, and Periaqueductal Gray Lesions on Short- and Long-Term Contextual Fear. Behavioral Neuroscience, 107, 1093-1098. http://www.ncbi.nlm.nih.gov/pubmed/8136063 
http://dx.doi.org/10.1037/0735-7044.107.6.1093

[31] Selden, N.R., Everitt, B.J., Jarrard, L.E. and Robbins, T.W. (1991) Complementary Roles for the Amygdala and Hippocampus in Aversive Conditioning to Explicit and Contextual Cues. Neuroscience, 42, 335-350. http://www.ncbi.nlm.nih.gov/pubmed/1832750 http://dx.doi.org/10.1016/0306-4522(91)90379-3

[32] Phillips, R.G. and LeDoux, J.E. (1994) Lesions of the Dorsal Hippocampal Formation Interfere with Background but Not Foreground Contextual Fear Conditioning. Learning \& Memory (Cold Spring Harbor, N.Y.), 1, 34-44. http://www.ncbi.nlm.nih.gov/pubmed/10467584

[33] Young, S.L., Bohenek, D.L. and Fanselow, M.S. (1994) NMDA Processes Mediate Anterograde Amnesia of Contextual Fear Conditioning Induced by Hippocampal Damage: Immunization against Amnesia by Context Preexposure. Behavioral Neuroscience, 108, 19-29. http://dx.doi.org/10.1037/0735-7044.108.1.19

[34] Kim, J. and Fanselow, M. (1992) Modality-Specific Retrograde Amnesia of Fear. Science, 256, 675-677. http://dx.doi.org/10.1126/science.1585183

[35] Parsons, T.C. and Otto, T. (2008) Temporary Inactivation of Dorsal Hippocampus Attenuates Explicitly Nonspatial, Unimodal, Contextual Fear Conditioning. Neurobiology of Learning and Memory, 90, 261-268. http://dx.doi.org/10.1016/j.nlm.2008.03.007

[36] Liu, X., Ramirez, S. and Tonegawa, S. (2014) Inception of a False Memory by Optogenetic Manipulation of a Hippocampal Memory Engram. Philosophical Transactions of the Royal Society B: Biological Sciences, 369, 20130142. http://dx.doi.org/10.1098/rstb.2013.0142

[37] Spiers, H.J. and Bendor, D. (2014) Enhance, Delete, Incept: Manipulating Hippocampus-Dependent Memories. Brain Research Bulletin, 105, 2-7. http://dx.doi.org/10.1016/j.brainresbull.2013.12.011

[38] Ramirez, S., Liu, X., Lin, P.A., Suh, J., Pignatelli, M., Redondo, R.L., et al. (2013) Creating a False Memory in the Hippocampus. Science, 341, 387-391. http://dx.doi.org/10.1126/science.1239073

[39] Adamec, R., Head, D., Soreq, H. and Blundell, J. (2008) The Role of the Read through Variant of Acetylcholinesterase in Anxiogenic Effects of Predator Stress in Mice. Behavioural Brain Research, 189, 180-190. http://dx.doi.org/10.1016/j.bbr.2007.12.023

[40] Mitra, R., Adamec, R. and Sapolsky, R. (2009) Resilience against Predator Stress and Dendritic Morphology of Amygdala Neurons. Behavioural Brain Research, 205, 535-543. http://dx.doi.org/10.1016/j.bbr.2009.08.014

[41] Apfelbach, R., Blanchard, C.D., Blanchard, R.J., Hayes, R.A. and McGregor, I.S. (2005) The Effects of Predator Odors in Mammalian Prey Species: A Review of Field and Laboratory Studies. Neuroscience \& Biobehavioral Reviews, 29, 1123-1144. http://dx.doi.org/10.1016/j.neubiorev.2005.05.005

[42] Blanchard, R.J., Blanchard, D.C., Rodgers, J. and Weiss, S.M. (1990) The Characterization and Modelling of Antipredator Defensive Behavior. Neuroscience \& Biobehavioral Reviews, 14, 463-472. http://dx.doi.org/10.1016/S0149-7634(05)80069-7

[43] Blanchard, R.J., Mast, M. and Blanchard, D.C. (1975) Stimulus Control of Defensive Reactions in the Albino Rat. Journal of Comparative and Physiological Psychology, 88, 81-88. http://dx.doi.org/10.1037/h0076213

[44] Blundell, J., Adamec, R. and Burton, P. (2005) Role of NMDA Receptors in the Syndrome of Behavioral Changes Produced by Predator Stress. Physiology \& Behavior, 86, 233-243. http://dx.doi.org/10.1016/j.physbeh.2005.07.012

[45] Blundell, J. and Adamec, R. (2006) Elevated pCREB in the PAG after Exposure to the Elevated plus Maze in Rats Previously Exposed to a Cat. Behavioural Brain Research, 175, 285-295. http://dx.doi.org/10.1016/j.bbr.2006.08.029

[46] Clay, R., Hebert, M., Gill, G., Stapleton, L.A., Pridham, A., Coady, M., et al. (2011) Glucocorticoids Are Required for Extinction of Predator Stress-Induced Hyperarousal. Neurobiology of Learning and Memory, 96, 367-377. http://dx.doi.org/10.1016/j.nlm.2011.06.012

[47] Dielenberg, R.A., Hunt, G.E. and McGregor, I.S. (2001) 'When a Rat Smells a Cat': The Distribution of Fos Immunoreactivity in Rat Brain Following Exposure to a Predatory Odor. Neuroscience, 104, 1085-1097. http://dx.doi.org/10.1016/S0306-4522(01)00150-6

[48] Fifield, K., Hebert, M., Williams, K., Linehan, V., Whiteman, J.D., Mac, C.P., et al. (2015) Time-Dependent Effects of Rapamycin on Consolidation of Predator Stress-Induced Hyperarousal. Behavioural Brain Research, 286, 104-111. http://dx.doi.org/10.1016/j.bbr.2015.02.045

[49] Mac Callum, P.E., Hebert, M., Adamec, R.E. and Blundell, J. (2014) Systemic Inhibition of mTOR Kinase via Rapamycin Disrupts Consolidation and Reconsolidation of Auditory Fear Memory. Neurobiology of Learning and Memory, 112, 176-185. http://dx.doi.org/10.1016/j.nlm.2013.08.014

[50] Masini, C.V., Sauer, S., White, J., Day, H.E. and Campeau, S. (2006) Non-Associative Defensive Responses of Rats to Ferret Odor. Physiology \& Behavior, 87, 72-81. http://dx.doi.org/10.1016/j.physbeh.2005.08.044 
[51] McGregor, I.S., Hargreaves, G.A., Apfelbach, R. and Hunt, G.E. (2004) Neural Correlates of Cat Odor-Induced Anxiety in Rats: Region-Specific Effects of the Benzodiazepine Midazolam. The Journal of Neuroscience, 24, 4134-4144. http://dx.doi.org/10.1523/JNEUROSCI.0187-04.2004

[52] Rosen, J.B. (2004) The Neurobiology of Conditioned and Unconditioned Fear: A Neurobehavioral System Analysis of the Amygdala. Behavioral and Cognitive Neuroscience Reviews, 3, 23-41. http://dx.doi.org/10.1177/1534582304265945

[53] Silva, B.A., Mattucci, C., Krzywkowski, P., Murana, E., Illarionova, A., Grinevich, V., et al. (2013) Independent Hypothalamic Circuits for Social and Predator Fear. Nature Neuroscience, 16, 1731-1733. http://dx.doi.org/10.1038/nn.3573

[54] Canteras, N.S., Mota-Ortiz, S.R. and Motta, S.C. (2012) What Ethologically Based Models Have Taught Us about the Neural Systems Underlying Fear and Anxiety. Brazilian Journal of Medical and Biological Research, 45, 321-327. http://dx.doi.org/10.1590/S0100-879X2012007500042

[55] Gross, C.T. and Canteras, N.S. (2012) The Many Paths to Fear. Nature Reviews Neuroscience, 13, 651-658. http://dx.doi.org/10.1038/nrn3301

[56] Carvalho-Netto, E.F., Martinez, R.C., Baldo, M.V. and Canteras, N.S. (2010) Evidence for the Thalamic Targets of the Medial Hypothalamic Defensive System Mediating Emotional Memory to Predatory Threats. Neurobiology of Learning and Memory, 93, 479-486. http://dx.doi.org/10.1016/j.nlm.2010.01.005

[57] De Lima, M.A., Baldo, M.V. and Canteras, N.S. (2016) A Role for the Anteromedial Thalamic Nucleus in the Acquisition of Contextual Fear Memory to Predatory Threats. Brain Structure and Function, 1-17. http://dx.doi.org/10.1007/s00429-016-1204-2

[58] Kincheski, G.C., Mota-Ortiz, S.R., Pavesi, E., Canteras, N.S. and Carobrez, A.P. (2012) The Dorsolateral Periaqueductal Gray and Its Role in Mediating Fear Learning to Life Threatening Events. PLoS ONE, 7, e50361. http://dx.doi.org/10.1371/journal.pone.0050361

[59] Diamond, D.M., Park, C.R., Heman, K.L. and Rose, G.M. (1999) Exposing Rats to a Predator Impairs Spatial Working Memory in the Radial Arm Water Maze. Hippocampus, 9, 542-552. http://dx.doi.org/10.1002/(SICI)1098-1063(1999)9:5<542::AID-HIPO8>3.0.CO;2-N

[60] Woodson, J.C., Macintosh, D., Fleshner, M. and Diamond, D.M. (2003) Emotion-Induced Amnesia in Rats: Working Memory-Specific Impairment, Corticosterone-Memory Correlation, and Fear versus Arousal Effects on Memory. Learning \& Memory, 10, 326-336. http://dx.doi.org/10.1101/lm.62903

[61] Zoladz, P.R., Park, C.R., Halonen, J.D., Salim, S., Alzoubi, K.H., Srivareerat, M., et al. (2012) Differential Expression of Molecular Markers of Synaptic Plasticity in the Hippocampus, Prefrontal Cortex, and Amygdala in Response to Spatial Learning, Predator Exposure, and Stress-Induced Amnesia. Hippocampus, 22, 577-589. http://dx.doi.org/10.1002/hipo.20922

[62] Mesches, M.H., Fleshner, M., Heman, K.L., Rose, G.M. and Diamond, D.M. (1999) Exposing Rats to a Predator Blocks Primed Burst Potentiation in the Hippocampus in Vitro. The Journal of Neuroscience, 19, RC18.

[63] Vouimba, R.-M., Muñoz, C. and Diamond, D.M. (2006) Differential Effects of Predator Stress and the Antidepressant Tianeptine on Physiological Plasticity in the Hippocampus and Basolateral Amygdala. Stress (Amsterdam, Netherlands), 9, 29-40. http://dx.doi.org/10.1080/10253890600610973

[64] Diamond, D.M., Campbell, A.M., Park, C.R., Halonen, J. and Zoladz, P.R. (2007) The Temporal Dynamics Model of Emotional Memory Processing: A Synthesis on the Neurobiological Basis of Stress-Induced Amnesia, Flashbulb and Traumatic Memories, and the Yerkes-Dodson Law. Neural Plasticity, 2007, Article ID: 60803. http://dx.doi.org/10.1155/2007/60803

[65] Diamond, D.M., Park, C.R., Campbell, A.M. and Woodson, J.C. (2005) Competitive Interactions between Endogenous LTD and LTP in the Hippocampus Underlie the Storage of Emotional Memories and Stress-Induced Amnesia. Hippocampus, 15, 1006-1025. http://dx.doi.org/10.1002/hipo.20107

[66] Diamond, D.M., Park, C.R. and Woodson, J.C. (2004) Stress Generates Emotional Memories and Retrograde Amnesia by Inducing an Endogenous Form of Hippocampal LTP. Hippocampus, 14, 281-291. http://dx.doi.org/10.1002/hipo.10186

[67] Daskalakis, N.P., Yehuda, R. and Diamond, D.M. (2013) Animal Models in Translational Studies of PTSD. Psychoneuroendocrinology, 38, 1895-1911. http://dx.doi.org/10.1016/j.psyneuen.2013.06.006

[68] Zoladz, P.R. and Diamond, D.M. (2016) Predator-Based Psychosocial Stress Animal Model of PTSD: Preclinical Assessment of Traumatic Stress at Cognitive, Hormonal, Pharmacological, Cardiovascular and Epigenetic Levels of Analysis. Experimental Neurology. (In Press)

[69] Seetharaman, S., Fleshner, M., Park, C.R. and Diamond, D.M. (2016) Influence of Daily Social Stimulation on Behavioral and Physiological Outcomes in an Animal Model of PTSD. Brain and Behavior, 6, e00458. 
http://dx.doi.org/10.1002/brb3.458

[70] Zoladz, P.R., Fleshner, M. and Diamond, D.M. (2013) Differential Effectiveness of Tianeptine, Clonidine and Amitriptyline in Blocking Traumatic Memory Expression, Anxiety and Hypertension in an Animal Model of PTSD. Progress in Neuro-Psychopharmacology and Biological Psychiatry, 44C, 1-16. http://dx.doi.org/10.1016/j.pnpbp.2013.01.001

[71] Zoladz, P.R., Fleshner, M. and Diamond, D.M. (2012) Psychosocial Animal Model of PTSD Produces a Long-Lasting Traumatic Memory, an Increase in General Anxiety and PTSD-Like Glucocorticoid Abnormalities. Psychoneuroendocrinology, 37, 1531-1545. http://dx.doi.org/10.1016/j.psyneuen.2012.02.007

[72] Zoladz, P.R., Park, C.R., Fleshner, M. and Diamond, D.M. (2015) Psychosocial Predator-Based Animal Model of PTSD Produces Physiological and Behavioral Sequelae and a Traumatic Memory Four Months Following Stress Onset. Physiology \& Behavior, 147, 183-192. http://dx.doi.org/10.1016/j.physbeh.2015.04.032

[73] Conrad, C.D., LeDoux, J.E., Magariños, A.M. and McEwen, B.S. (1999) Repeated Restraint Stress Facilitates Fear Conditioning Independently of Causing Hippocampal CA3 Dendritic Atrophy. Behavioral Neuroscience, 113, 902-913. http://www.ncbi.nlm.nih.gov/pubmed/10571474 http://dx.doi.org/10.1037/0735-7044.113.5.902

[74] Miracle, A.D., Brace, M.F., Huyck, K.D., Singler, S.A. and Wellman, C.L. (2006) Chronic Stress Impairs Recall of Extinction of Conditioned Fear. Neurobiology of Learning and Memory, 85, 213-218. http://dx.doi.org/10.1016/j.nlm.2005.10.005

[75] Sandi, C., Merino, J.J., Cordero, M.I., Touyarot, K. and Venero, C. (2001) Effects of Chronic Stress on Contextual Fear Conditioning and the Hippocampal Expression of the Neural Cell Adhesion Molecule, Its Polysialylation, and L1. Neuroscience, 102, 329-339. http://www.ncbi.nlm.nih.gov/pubmed/11166119 http://dx.doi.org/10.1016/s0306-4522(00)00484-X

[76] Ghizoni, D.M., Pavanati, K.C.A., Arent, A.M., Machado, C., Faria, M.S., Pinto, C.M.H., Gasparotto, O.C., et al. (2006) Alterations in Glutathione Levels of Brain Structures Caused by Acute Restraint Stress and by Nitric Oxide Synthase Inhibition but Not by Intraspecific Agonistic Interaction. Behavioural Brain Research, 166, 71-77. http://dx.doi.org/10.1016/j.bbr.2005.07.005

[77] Murakami, S., Imbe, H., Morikawa, Y., Kubo, C. and Senba, E. (2005) Chronic Stress, as Well as Acute Stress, Reduces BDNF mRNA Expression in the Rat Hippocampus but Less Robustly. Neuroscience Research, 53, 129-139. http://dx.doi.org/10.1016/j.neures.2005.06.008

[78] Rage, F., Givalois, L., Marmigère, F., Tapia-Arancibia, L. and Arancibia, S. (2002) Immobilization Stress Rapidly Modulates BDNF mRNA Expression in the Hypothalamus of Adult Male Rats. Neuroscience, 112, 309-318.

http://www.ncbi.nlm.nih.gov/pubmed/12044449 http://dx.doi.org/10.1016/S0306-4522(02)00072-6

[79] Trnecková, L., Armario, A., Hynie, S., Sída, P. and Klenerová, V. (2006) Differences in the Brain Expression of c-fos mRNA after Restraint Stress in Lewis Compared to Sprague-Dawley Rats. Brain Research, 1077, 7-15. http://dx.doi.org/10.1016/j.brainres.2006.01.029

[80] Makino, S., Smith, M.A. and Gold, P.W. (2002) Regulatory Role of Glucocorticoids and Glucocorticoid Receptor mRNA Levels on Tyrosine Hydroxylase Gene Expression in the Locus Coeruleus during Repeated Immobilization Stress. Brain Research, 943, 216-223. http://www.ncbi.nlm.nih.gov/pubmed/12101044 http://dx.doi.org/10.1016/s0006-8993(02)02647-1

[81] Marlin, N.A. (1982) Contextual Associations in Trace Conditioning. Animal Learning \& Behavior, 9, 519-523. http://dx.doi.org/10.3758/BF03209784

[82] Mcechron, M.D., Bouwmeester, H., Tseng, W., Weiss, C. and Disterhoft, J.F. (1998) Hippocampectomy Disrupts Auditory Trace Fear Conditioning and Contextual Fear Conditioning in the Rat. Hippocampus, 646, 638-646.

[83] Bryant, R.A., O’Donnell, M.L., Creamer, M., McFarlane, A.C. and Silove, D. (2011) Posttraumatic Intrusive Symptoms across Psychiatric Disorders. Journal of Psychiatric Research, 45, 842-847. http://dx.doi.org/10.1016/j.jpsychires.2010.11.012

[84] Michael, T., Ehlers, A., Halligan, S.L. and Clark, D.M. (2005) Unwanted Memories of Assault: What Intrusion Characteristics Are Associated with PTSD? Behaviour Research and Therapy, 43, 613-628. http://dx.doi.org/10.1016/j.brat.2004.04.006

[85] Shapiro, M.L. and Eichenbaum, H. (1999) Hippocampus as a Memory Map: Synaptic Plasticity and Memory Encoding by Hippocampal Neurons. Hippocampus, 9, 365-384. http://dx.doi.org/10.1002/(SICI)1098-1063(1999)9:4<365::AID-HIPO4>3.0.CO;2-T

[86] Bunsey, M. and Eichenbaum, H. (1996) Conservation of Hippocampal Memory Function in Rats and Humans. Nature, 379, 255-257. http://dx.doi.org/10.1038/379255a0 
[87] Eichenbaum, H. (2004) Hippocampus: Cognitive Processes and Neural Representations that Underlie Declarative Memory. Neuron, 44, 109-120.

[88] Anagnostaras, S.G., Maren, S. and Fanselow, M.S. (1999) Temporally Graded Retrograde Amnesia of Contextual Fear after Hippocampal Damage in Rats: Within-Subjects Examination. The Journal of Neuroscience: The Official Journal of the Society for Neuroscience, 19, 1106-1114. http://www.ncbi.nlm.nih.gov/pubmed/9920672

[89] Rogers, J.L., Hunsaker, M.R. and Kesner, R.P. (2006) Effects of Ventral and Dorsal CA1 Subregional Lesions on Trace Fear Conditioning. Neurobiology of Learning and Memory, 86, 72-81. http://dx.doi.org/10.1016/j.nlm.2006.01.002

[90] Holt, W. and Maren, S. (1999) Muscimol Inactivation of the Dorsal Hippocampus Impairs Contextual Retrieval of Fear Memory. The Journal of Neuroscience, 19, 9054-9062.

[91] Pentkowski, N.S., Blanchard, D.C., Lever, C., Litvin, Y. and Blanchard, R.J. (2006) Effects of Lesions to the Dorsal and Ventral Hippocampus on Defensive Behaviors in Rats. The European Journal of Neuroscience, 23, 2185-2196. http://dx.doi.org/10.1111/j.1460-9568.2006.04754.x

[92] Goel, N., Rao, H., Durmer, J.S. and Dinges, D.F. (2009) Neurocognitive Consequences of Sleep Deprivation. Seminars in Neurology, 29, 320-339. http://dx.doi.org/10.1055/s-0029-1237117

[93] McEwen, B.S. (2006) Sleep Deprivation as a Neurobiologic and Physiologic Stressor: Allostasis and Allostatic Load. Metabolism, 55, S20-S23. http://dx.doi.org/10.1016/j.metabol.2006.07.008

[94] Harrison, Y. and Horne, J.A. (1998) Sleep Loss Impairs Short and Novel Language Tasks Having a Prefrontal Focus. Journal of Sleep Research, 7, 95-100. http://www.ncbi.nlm.nih.gov/pubmed/9682180 http://dx.doi.org/10.1046/j.1365-2869.1998.00104.x

[95] Harrison, Y. and Horne, J.A. (2000) The Impact of Sleep Deprivation on Decision Making: A Review. Journal of Experimental Psychology: Applied, 6, 236-249. http://www.ncbi.nlm.nih.gov/pubmed/11014055 http://dx.doi.org/10.1037/1076-898x.6.3.236

[96] Kleitman, N. (1987) Sleep and Wakefulness. The University of Chicago Press, Chicago, 560.

[97] Kribbs, N.B. and Dinges, D. (1994) Vigilance Decrement and Sleepiness. Sleep Onset: Normal and Abnormal Processes. In: Harsh, J. and Ogilvie, R., Eds., Sleep Onset Mechanisms, American Psychological Association, Washington DC, 113-125.

[98] Patrick, G. and Gilbert, J. (1896) On the Effects of Loss of Sleep. Psychological Review, 3, 469-483

[99] Pilcher, J.J. and Huffcutt, A.J. (1996) Effects of Sleep Deprivation on Performance: A Meta-Analysis. Sleep, 19, 318326. http://psycnet.apa.org/psycinfo/1997-07865-006

[100] Van Dongen, H.P.A., Maislin, G., Mullington, J.M. and Dinges, D.F. (2003) The Cumulative Cost of Additional Wakefulness: Dose-Response Effects on Neurobehavioral Functions and Sleep Physiology from Chronic Sleep Restriction and Total Sleep Deprivation. Sleep, 26, 117-126. http://www.ncbi.nlm.nih.gov/pubmed/12683469

[101] Graves, L.A., Heller, E.A., Pack, A.I. and Abel, T. (2003) Sleep Deprivation Selectively Impairs Memory Consolidation for Contextual Fear Conditioning. Learning \& Memory, 10, 168-176. http://dx.doi.org/10.1101/lm.48803

[102] Hagewoud, R., Havekes, R., Novati, A., Keijser, J.N., Van der Zee, E.A. and Meerlo, P. (2010) Sleep Deprivation Impairs Spatial Working Memory and Reduces Hippocampal AMPA Receptor Phosphorylation. Journal of Sleep Research, 19, 280-288. http://dx.doi.org/10.1111/j.1365-2869.2009.00799.x

[103] Ruskin, D.N. and Lahoste, G.J. (2008) Aspects of Learned Fear Related to the Hippocampus Are Sleep-Dependent. Behavioural Brain Research, 191, 67-71. http://dx.doi.org/10.1016/j.bbr.2008.03.011

[104] Ruskin, D.N., Liu, C., Dunn, K.E., Bazan, N.G. and Lahoste, G.J. (2004) SHORT COMMUNICATION Sleep Deprivation Impairs Hippocampus-Mediated Contextual Learning but Not Amygdala-Mediated Cued Learning in Rats. Neuroscience, 19, 3121-3124.

[105] Youngblood, B.D., Zhou, J., Smagin, G.N., Ryan, D.H. and Harris, R.B. (1997) Sleep Deprivation by the "Flower Pot” Technique and Spatial Reference Memory. Physiology \& Behavior, 61, 249-256. http://dx.doi.org/10.1016/S0031-9384(96)00363-0

[106] Hagewoud, R., Bultsma, L.J., Barf, R.P., Koolhaas, J.M. and Meerlo, P. (2011) Sleep Deprivation Impairs Contextual Fear Conditioning and Attenuates Subsequent Behavioural, Endocrine and Neuronal Responses. Journal of Sleep Research, 20, 259-266. http://dx.doi.org/10.1111/j.1365-2869.2010.00895.x

[107] Adamec, R., Holmes, A. and Blundell, J. (2008) Vulnerability to Lasting Anxiogenic Effects of Brief Exposure to Predator Stimuli: Sex, Serotonin and Other Factors-Relevance to PTSD. Neuroscience \& Biobehavioral Reviews, 32, 1287-1292. http://dx.doi.org/10.1016/j.neubiorev.2008.05.005

[108] Canteras, N.S. and Graeff, F.G. (2014) Executive and Modulatory Neural Circuits of Defensive Reactions: Implications for Panic Disorder. Neuroscience \& Biobehavioral Reviews, 46, 352-364. 
http://dx.doi.org/10.1016/j.neubiorev.2014.03.020

[109] Matar, M.A., Zohar, J. and Cohen, H. (2013) Translationally Relevant Modeling of PTSD in Rodents. Cell and Tissue Research, 354, 127-139. http://dx.doi.org/10.1007/s00441-013-1687-6

[110] Rosen, J.B., Pagani, J.H., Rolla, K.L. and Davis, C. (2008) Analysis of Behavioral Constraints and the Neuroanatomy of Fear to the Predator Odor Trimethylthiazoline: A Model for Animal Phobias. Neuroscience \& Biobehavioral Reviews, 32, 1267-1276. http://dx.doi.org/10.1016/j.neubiorev.2008.05.006

[111] Takahashi, L.K., Chan, M.M. and Pilar, M.L. (2008) Predator Odor Fear Conditioning: Current Perspectives and New Directions. Neuroscience and Biobehavioral Reviews, 32, 1218-1227. http://dx.doi.org/10.1016/j.neubiorev.2008.06.001

[112] Cordero, M.I., Merino, J.J. and Sandi, C. (1998) Correlational Relationship between Shock Intensity and Corticosterone Secretion on the Establishment and Subsequent Expression of Contextual Fear Conditioning. Behavioral Neuroscience, 112, 885-891. http://www.ncbi.nlm.nih.gov/pubmed/9733194 http://dx.doi.org/10.1037/0735-7044.112.4.885

[113] Weiss, J.M., Krieckhaus, E.E. and Conte, R. (1968) Effects of Fear Conditioning on Subsequent Avoidance Behavior and Movement. Journal of Comparative and Physiological Psychology, 65, 413-421. http://www.ncbi.nlm.nih.gov/pubmed/5667381 http://dx.doi.org/10.1037/h0025832

[114] Yerkes, R.M. and Dodson, J.D. (1908) The Relation of Strength of Stimulus to Rapidity of Habit-Formation. Journal of Comparative Neurology and Psychology, 18, 459-482. http://dx.doi.org/10.1002/cne.920180503

[115] Fanselow, M.S. and Gale, G.D. (2003) The Amygdala, Fear, and Memory. Amygdala in Brain Function: Basic and Clinical Approaches, 985, 125-134. http://dx.doi.org/10.1111/j.1749-6632.2003.tb07077.x

[116] Rudy, J.W., Huff, N.C. and Matus-Amat, P. (2004) Understanding Contextual Fear Conditioning: Insights from a Two-Process Model. Neuroscience \& Biobehavioral Reviews, 28, 675-685. http://dx.doi.org/10.1016/j.neubiorev.2004.09.004

[117] Bryant, R.A. and Harvey, A.G. (1996) Visual Imagery in Posttraumatic Stress Disorder. Journal of Traumatic Stress, 9, 613-619. http://dx.doi.org/10.1002/jts.2490090317

[118] Cuthbert, B.N., Lang, P.J., Strauss, C., Drobes, D., Patrick, C.J. and Bradley, M.M. (2003) The Psychophysiology of Anxiety Disorder: Fear Memory Imagery. Psychophysiology, 40, 407-422. http://dx.doi.org/10.1111/1469-8986.00043

[119] Jacobs, W.J. and Nadel, L. (1985) Stress-Induced Recovery of Fears and Phobias. Psychological Review, 92, $512-531$. http://dx.doi.org/10.1037/0033-295X.92.4.512

[120] Wild, J., Hackmann, A. and Clark, D.M. (2007) When the Present Visits the Past: Updating Traumatic Memories in Social Phobia. Journal of Behavior Therapy and Experimental Psychiatry, 38, 386-401. http://dx.doi.org/10.1016/j.jbtep.2007.07.003

[121] Cordero, M.I., Venero, C., Kruyt, N. and Sandi, C. (2003) Prior Exposure to a Single Stress Session Facilitates Subsequent Contextual Fear Conditioning in Rats: Evidence for a Role of Corticosterone. Hormones and Behavior, 44, 338345. http://dx.doi.org/10.1016/S0018-506X(03)00160-0

[122] Maier, S.F. (1990) Role of Fear in Mediating Shuttle Escape Learning Deficit Produced by Inescapable Shock. Journal of Experimental Psychology: Animal Behavior Processes, 16, 137-149. http://dx.doi.org/10.1037/0097-7403.16.2.137

[123] Rau, V., DeCola, J.P. and Fanselow, M.S. (2005) Stress-Induced Enhancement of Fear Learning: An Animal Model of Posttraumatic Stress Disorder. Neuroscience \& Biobehavioral Reviews, 29, 1207-1223. http://dx.doi.org/10.1016/j.neubiorev.2005.04.010

[124] Shors, T.J., Weiss, C. and Thompson, R.F. (1992) Stress-Induced Facilitation of Classical Conditioning. Science, 257, 537-539. http://dx.doi.org/10.1126/science.1636089

[125] Van der Kolk, B.A. and Fisler, R. (1995) Dissociation and the Fragmentary Nature of Traumatic Memories: Overview and Exploratory Study. Journal of Traumatic Stress, 8, 505-525. http://dx.doi.org/10.1002/jts.2490080402

[126] Corley, M.J., Caruso, M.J. and Takahashi, L.K. (2011) Stress-Induced Enhancement of Fear Conditioning and Sensitization Facilitates Extinction-Resistant and Habituation-Resistant Fear Behaviors in a Novel Animal Model of Posttraumatic Stress Disorder. Physiology \& Behavior, 105, 408-416. http://dx.doi.org/10.1016/j.physbeh.2011.08.037

[127] Cohen, H., Kaplan, Z., Matar, M.A., Loewenthal, U., Kozlovsky, N. and Zohar, J. (2006) Anisomycin, a Protein Synthesis Inhibitor, Disrupts Traumatic Memory Consolidation and Attenuates Posttraumatic Stress Response in Rats. Biological Psychiatry, 60, 767-776. http://dx.doi.org/10.1016/j.biopsych.2006.03.013

[128] Cohen, H., Matar, M.A., Buskila, D., Kaplan, Z. and Zohar, J. (2008) Early Post-Stressor Intervention with High-Dose Corticosterone Attenuates Posttraumatic Stress Response in an Animal Model of Posttraumatic Stress Disorder. Biological Psychiatry, 64, 708-717. http://dx.doi.org/10.1016/j.biopsych.2008.05.025 
[129] Matar, M.A., Zohar, J., Kaplan, Z. and Cohen, H. (2009) Alprazolam Treatment Immediately after Stress Exposure Interferes with the Normal HPA-Stress Response and Increases Vulnerability to Subsequent Stress in an Animal Model of PTSD. European Neuropsychopharmacology, 19, 283-295. http://dx.doi.org/10.1016/j.euroneuro.2008.12.004

[130] Zohar, J., Matar, M.A., Ifergane, G., Kaplan, Z. and Cohen, H. (2008) Brief Post-Stressor Treatment with Pregabalin in an Animal Model for PTSD: Short-Term Anxiolytic Effects without Long-Term Anxiogenic Effect. European Neuropsychopharmacology, 18, 653-666. http://dx.doi.org/10.1016/j.euroneuro.2008.04.009

[131] Pavlov, I.P. (1928) Conditioned Reflexes. Oxford University Press, London.

[132] Blanchard, D.C., Canteras, N.S., Markham, C.M., Pentkowski, N.S. and Blanchard, R.J. (2005) Lesions of Structures Showing FOS Expression to Cat Presentation: Effects on Responsivity to a Cat, Cat Odor, and Nonpredator Threat. Neuroscience and Biobehavioral Reviews, 29, 1243-1253. http://dx.doi.org/10.1016/j.neubiorev.2005.04.019

[133] Akirav, I., Sandi, C. and Richter-Levin, G. (2001) Differential Activation of Hippocampus and Amygdala Following Spatial Learning under Stress. The European Journal of Neuroscience, 14, 719-725.

http://www.ncbi.nlm.nih.gov/pubmed/11556896 http://dx.doi.org/10.1046/j.0953-816x.2001.01687.x

[134] Artola, A., von Frijtag, J.C., Fermont, P.C.J., Gispen, W.H., Schrama, L.H., Kamal, A. and Spruijt, B.M. (2006) LongLasting Modulation of the Induction of LTD and LTP in Rat Hippocampal CA1 by Behavioural Stress and Environmental Enrichment. The European Journal of Neuroscience, 23, 261-272. http://dx.doi.org/10.1111/j.1460-9568.2005.04552.x

[135] Cao, J., Chen, N., Xu, T. and Xu, L. (2004) Stress-Facilitated LTD Induces Output Plasticity through SynchronizedSpikes and Spontaneous Unitary Discharges in the CA1 Region of the Hippocampus. Neuroscience Research, 49, 229239. http://dx.doi.org/10.1016/j.neures.2004.03.001

[136] Kim, J.J., Foy, M.R. and Thompson, R.F. (1996) Behavioral Stress Modifies Hippocampal Plasticity through NMDA Receptor Activation. Neurobiology, 93, 4750-4753.

[137] Inoue, K., Fukazawa, Y., Ogura, A. and Inokuchi, K. (2005) Two-Dimensional Neural Activity Mapping of the Entire Population of Hippocampal CA1 Pyramidal Cells Responding to Fear Conditioning. Neuroscience Research, 51, 417425. http://dx.doi.org/10.1016/j.neures.2004.12.012

[138] Strekalova, T., Zorner, B., Zacher, C., Sadovska, G., Herdegen, T. and Gass, P. (2003) Memory Retrieval after Contextual Fear Conditioning Induces c-Fos and JunB Expression in CA1 Hippocampus. Genes, Brain and Behavior, 2, 3-10. http://dx.doi.org/10.1034/j.1601-183X.2003.00001.x

[139] Zhou, M., Conboy, L., Sandi, C., Joels, M. and Krugers, H.J. (2009) Fear Conditioning Enhances Spontaneous AMPA Receptor-Mediated Synaptic Transmission in Mouse Hippocampal CA1 Area. European Journal of Neuroscience, 30, 1559-1564. http://dx.doi.org/10.1111/j.1460-9568.2009.06951.x

[140] Lee, I. and Kesner, R.P. (2004) Differential Contributions of Dorsal Hippocampal Subregions to Memory Acquisition and Retrieval in Contextual Fear-Conditioning. Hippocampus, 14, 301-310. http://dx.doi.org/10.1002/hipo.10177

[141] Sakaguchi, M., Kim, K., Yu, L.M., Hashikawa, Y., Sekine, Y., Okumura, Y., et al. (2015) Inhibiting the Activity of CA1 Hippocampal Neurons Prevents the Recall of Contextual Fear Memory in Inducible ArchT Transgenic Mice. PLoS ONE, 10, e0130163. http://dx.doi.org/10.1371/journal.pone.0130163

[142] Rossi, V.C., Tiba, P.A., Moreira, K.D., Ferreira, T.L., Oliveira, M.G. and Suchecki, D. (2014) Effects of Sleep Deprivation on Different Phases of Memory in the Rat: Dissociation between Contextual and Tone Fear Conditioning Tasks. Frontiers in Behavioral Neuroscience, 8, 389. http://dx.doi.org/10.3389/fnbeh.2014.00389

[143] Bryant, R., Creamer, M., O’Donnell, M., Silove, D. and McFarlane, A.C. (2010) Sleep disturbance immediately prior to trauma predicts subsequent psychiatric disorder. Sleep, 33, 69-74.

[144] Shapiro, C.M., Flanigan, M., Fleming, J.A.E., Morehouse, R., Moscovitch, A., Plamondon, J., Reinish, L., et al. (2002) Development of an Adjective Checklist to Measure Five FACES of Fatigue and Sleepiness. Data from a National Survey of Insomniacs. Journal of Psychosomatic Research, 52, 467-473. http://www.ncbi.nlm.nih.gov/pubmed/12069871 http://dx.doi.org/10.1016/S0022-3999(02)00407-5

[145] Moul, D.E., Nofzinger, E.A., Pilkonis, P.A., Houck, P.R., Miewald, J.M. and Buysse, D.J. (2002) Symptom Reports in Severe Chronic Insomnia. Sleep, 25, 553-563. http://ukpmc.ac.uk/abstract/MED/12150322

[146] Liberzon, I. and Sripada, C.S. (2008) The Functional Neuroanatomy of PTSD: A Critical Review. Progress in Brain Research, 167, 151-169. http://dx.doi.org/10.1016/S0079-6123(07)67011-3

[147] Krakow, B., Melendrez, D., Warner, T.D., Dorin, R., Harper, R. and Hollifield, M. (2002) To Breathe, Perchance to Sleep: Sleep-Disordered Breathing and Chronic Insomnia among Trauma Survivors. Sleep and Breathing, 6, 189-202. http://dx.doi.org/10.1055/s-2002-36593

[148] Neylan, T.C., Mueller, S.G., Wang, Z., Metzler, T.J., Lenoci, M., Truran, D., et al. (2010) Insomnia Severity Is Associated with a Decreased Volume of the CA3/Dentate Gyrus Hippocampal Subfield. Biological Psychiatry, 68, 494-496. 
http://dx.doi.org/10.1016/j.biopsych.2010.04.035

[149] Bracha, H.S. (2006) Human Brain Evolution and the “Neuroevolutionary Time-Depth Principle:” Implications for the Reclassification of Fear-Circuitry-Related Traits in DSM-V and for Studying Resilience to Warzone-Related Posttraumatic Stress Disorder. Progress in Neuro-Psychopharmacology \& Biological Psychiatry, 30, 827-853. http://dx.doi.org/10.1016/j.pnpbp.2006.01.008

[150] Yoo, S.-S., Hu, P.T., Gujar, N., Jolesz, F.A. and Walker, M.P. (2007) A Deficit in the Ability to Form New Human Memories without Sleep. Nature Neuroscience, 10, 385-392. http://dx.doi.org/10.1038/nn1851

[151] Bonnet, M.H. and Arand, D.L. (2002) Level of Arousal and the Ability to Maintain Wakefulness. Journal of Sleep Research, 8, 247-254. http://dx.doi.org/10.1046/j.1365-2869.1999.00168.x

[152] Wilent, W.B., Oh, M.Y., Buetefisch, C.M., Bailes, J.E., Cantella, D., Angle, C., et al. (2010) Induction of Panic Attack by Stimulation of the Ventromedial Hypothalamus. Journal of Neurosurgery, 112, 1295-1298. http://dx.doi.org/10.3171/2009.9.JNS09577

\section{Submit or recommend next manuscript to SCIRP and we will provide best service for you:}

Accepting pre-submission inquiries through Email, Facebook, Linkedin, Twitter, etc A wide selection of journals (inclusive of 9 subjects, more than 200 journals)

Providing a 24-hour high-quality service

User-friendly online submission system

Fair and swift peer-review system

Efficient typesetting and proofreading procedure

Display of the result of downloads and visits, as well as the number of cited articles

Maximum dissemination of your research work

Submit your manuscript at: http://papersubmission.scirp.org/ 